\title{
Nerve fibre layer loss in diseases of the outer retinal layer
}

\author{
NANCY M NEWMAN,' ROSALIND A STEVENS,! AND JOHN R HECKENLIVELY ${ }^{2}$ \\ From the Departments of Ophthalmology of the 'Pacific Presbyterian Medical Center, San Francisco, and the \\ ${ }^{2} J u l e s$ Stein Eye Institute, UCLA School of Medicine, Los Angeles, California, USA
}

SUMMARY We present examples of nerve fibre layer changes in diseases thought to affect primarily the outer retinal layers. These disease processes include cone-rod dystrophies, rod-cone dystrophies, juvenile macular degeneration (Stargardt's disease) and fundus flavimaculatis, vitelliform macular dystrophy, and Leber's congenital amaurosis. All were associated with alterations in the retinal nerve fibre layer, either diffuse or focal. The presence of these nerve fibre layer changes raises the question of transsynaptic degeneration and of possible primary or associated disease of other retinal cells than the receptors-namely, bipolar, amacrine, Mueller, or ganglion cells-in these diseases of the outer retinal layer. Involvement of the nerve fibre layer also indicates the need to examine patients with defects in the nerve fibre layer by electroretinograms and other tests for outer retinal layer disease when no obvious optic nerve disease is present.

Clinically manifest damage to the anterior visual afferent pathways, especially the optic nerve, usually causes visible changes in the retinal nerve fibre layer. Not infrequently loss of the retinal nerve fibre layer gives the first clue of optic nerve compromise in glaucoma or multiple sclerosis and precedes the clinical manifestations, visual symptoms, or the visual field deficits. ${ }^{1-3}$ The changes in the retinal nerve fibre layer secondary to optic atrophy are quantitative changes, which appear as diffuse or focal atrophy of the nerve fibre layer. ${ }^{4}$ Qualitative changes in the nerve fibres themselves may be seen prior to optic atrophy and are characteristic of some diseases, such as Leber's hereditary optic atrophy. ${ }^{5}$

A number of ocular disorders known to involve primarily or exclusively the outer retinal layers are also associated with atrophic changes in the nerve fibre layer. To illustrate this point we present below examples of retinal receptor and/or pigment epithelium disorders associated with loss of the nerve fibre layer. Rake and wedge defects and diffuse nerve fibre changes are demonstrated in cone-rod dystrophies, rod-cone dystrophies (retinitis pigmentosa), juvenile macular degeneration, fundus flavimaculatus (Stargardt's disease), vitelliform macular dystrophy, and Leber's congenital amaurosis.

Correspondence to Dr Nancy $M$ Newman, Department of Ophthalmology, Pacific Presbyterian Medical Center, PO Box 7999, San Francisco, CA 94120, USA.

\section{Subjects and materials}

Patients with various types of retinal degeneration who clearly showed nerve fibre loss were selected from our files. In each case the diagnosis was made after a careful medical and family history and ophthalmic examination consisting of external and slit-lamp examination and direct and indirect ophthalmoscopy. In selected cases fluorescein angiography, electroretinography (ERG), electrooculography (EOG), and dark adaptometry by standardised techniques were performed. ${ }^{67}$ All the findings were analysed to arrive at the most accurate diagnosis. A summary of the diagnoses and pertinent clinical findings can be found in Table 1.

\section{Results}

Fig. 1A-H. Patients 1-8 with outer retinal layer disease. All show rake defects (dark striations within grey translucent areas of more normal retinal nerve fibre layer (some arrowed) in temporal arcades and loss of retinal nerve fibre layer detail in the papillomacular bundle. Defects are less distinct than on funduscopy, as the prints are copies of colour transparencies. The diagnoses of the patients are given under the individual Figs.

Patient 1. A 25-year-old male with vitelliform macular dystrophy had best corrected vision acuity of 
Table 1 Details of patients

\begin{tabular}{|c|c|c|c|c|c|}
\hline Patient & Age & Diagnosis & $\begin{array}{l}\text { Visual } \\
\text { acuity }\end{array}$ & Electro-retinogram & Goldmann fields \\
\hline 1 & 25 & Vitelliform dystrophy & $\begin{array}{l}20 / 20 \\
20 / 50\end{array}$ & Normal & $\begin{array}{l}\text { Minimal central depression OD; relative } \\
\text { central and paracentral scotomata OS }\end{array}$ \\
\hline 2 & 26 & Simplex cone-rod dystrophy & $\begin{array}{l}20 / 30 \\
20 / 40\end{array}$ & $\begin{array}{l}1 / 3 \text { of normal, photopic worse } \\
\text { affected }\end{array}$ & $\begin{array}{l}\text { Baring of blindspot; partial ring scotoma } \\
\text { superiorly, contracted OU }\end{array}$ \\
\hline 3 & 31 & Dominant cone-rod dystrophy & $\begin{array}{l}20 / 200 \\
20 / 100\end{array}$ & Barely recordable & Pseudoaltitudinal defect $\mathrm{OU}$ \\
\hline 4 & 7 & $\begin{array}{l}\text { Juvenile Leber's congenital } \\
\text { amaurosis }\end{array}$ & $\begin{array}{l}20 / 70 \\
20 / 60\end{array}$ & Unrecordable & Less than $10^{\circ}$ to IV OU \\
\hline 5 & 22 & Stargardt's disease & $\begin{array}{l}20 / 40 \\
20 / 50\end{array}$ & Normal & Full with central scotomata OU \\
\hline 6 & 33 & Rod-cone dystrophy & $\begin{array}{l}20 / 20 \\
20 / 30\end{array}$ & Barely recordable & $\begin{array}{l}\text { Small central fields with peripheral islands } \\
\text { OU }\end{array}$ \\
\hline 7 & 7 & Fundus flavimaculatus & $\begin{array}{l}20 / 80 \\
\mathrm{OU}\end{array}$ & Normal & Normal \\
\hline 8 & 44 & Choroideraemia (carrier) & $\begin{array}{l}20 / 30 \\
\text { OU }\end{array}$ & Borderline normal & Normal \\
\hline
\end{tabular}

20/20 in the right eye and 20/50 in the left (Fig. 1A). ERG and dark adaptation were within normal limits, though the cone portion of the dark adaptation curve was somewhat low. The EOG was abnormal, with light peak to dark trough $(\mathrm{Lp} / \mathrm{Dt})$ ratios of 1.2 on the right and 1.35 on the left.

Patient 2 was a 26-year-old woman with cone-rod degeneration. Her visual acuity was $20 / 30$ on the right and 20/40 on the left (Fig. 1B). The ERG showed a barely recordable photopic response, one-third normal scotopic responses, and unrecordable flicker responses. Visual fields showed baring of the blind spot and partial ring scotomata (Figs. 2 and 3 ).

Patient 3 was a 31-year-old woman with cone-rod degeneration of the autosomal dominant type. She had a visual acuity of 20/200 on the right and 20/100 on the left (Fig. 1C). The photopic ERG was barely recordable, the scotopic ERG one-half normal.

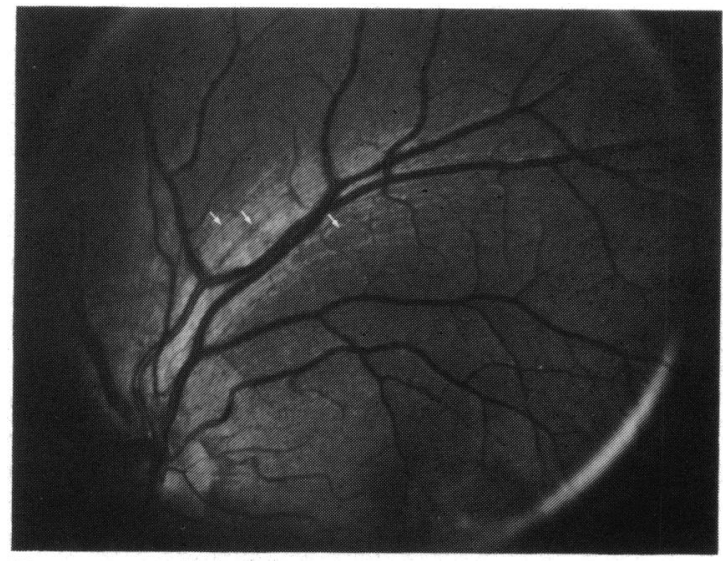

Fig. 1A Vitelliform dystrophy.
Visual fields showed pseudoaltitudinal defects with smaller isoptres in the right eye (Fig. 4).

Patient 4 was a 7-year-old with juvenile Leber's amaurosis. ${ }^{8}$ Visual acuity was $20 / 70$ on the right and 20/60 on the left (Fig. 1D). The ERG was unrecordable. The Goldmann field was less than $10^{\circ}$ to a I-4 target.

Patient 5 was a 22-year-old male with fundus flavimaculatus (Fig. 1E). Visual acuity was 20/40 on the right and 20/50 on the left. The ERG was normal. The EOG showed $155 \%$ rise. Visual fields were full, with central scotomata.

Patient 6 was a 33-year-old man with rod-cone degeneration (Fig. 1F). Visual acuity was $20 / 20$ on the right and 20/30 on the left. The photopic and

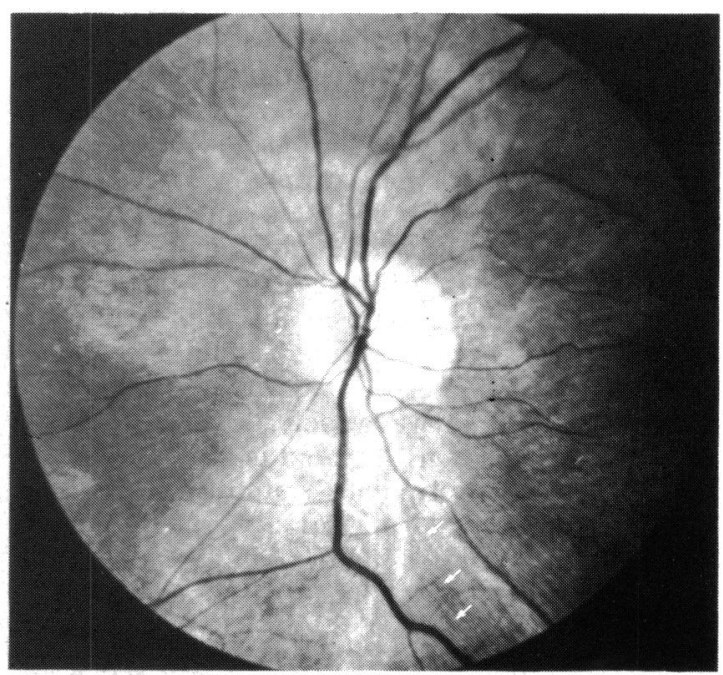

Fig. 1B Cone-rod dystrophy. 


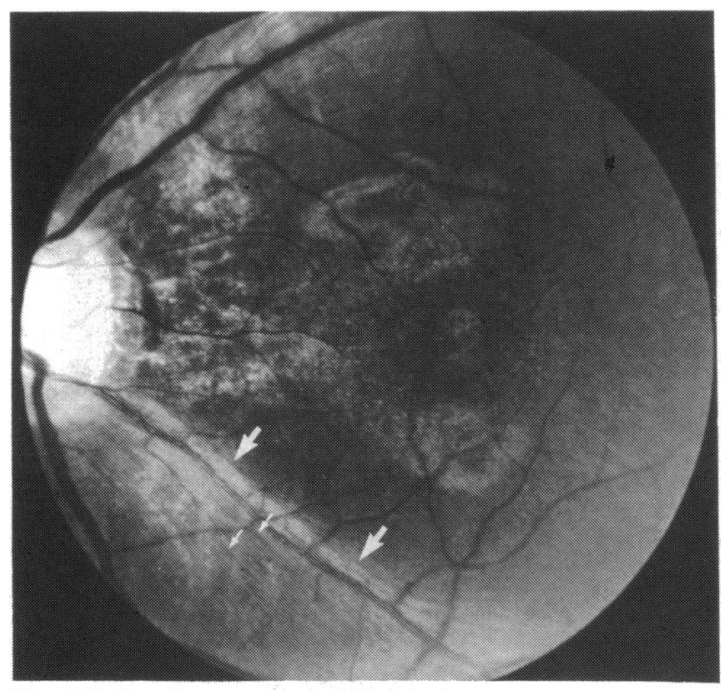

Fig. 1C Dominant cone-rod dystrophy.

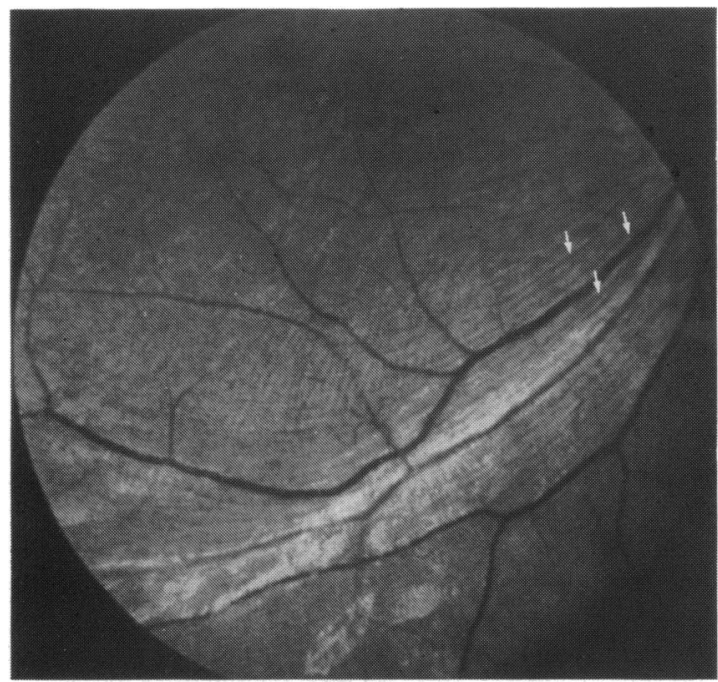

Fig. 1D Leber's congenital amaurosis.

scotopic ERGs were barely recordable. Dark adaptation was $4.25 \log$ units elevated at 40 minutes. The visual field showed small central fields with very large ring scotomata and large peripheral islands (Fig. 5).

Patient 7 was a 7-year-old girl with fundus flavimaculatus (Fig. 1G). Visual acuity was 20/80 OU. The ERGs were normal bilaterally, as were the Goldmann fields.

Patient 8 was a 44-year-old woman who was a carrier of choroideraemia (Fig. 1H). Visual acuity was 20/30 in each eye. The photopic ERG was borderline and the scotopic ERG normal on the right and borderline on the left. The dark adaptation was

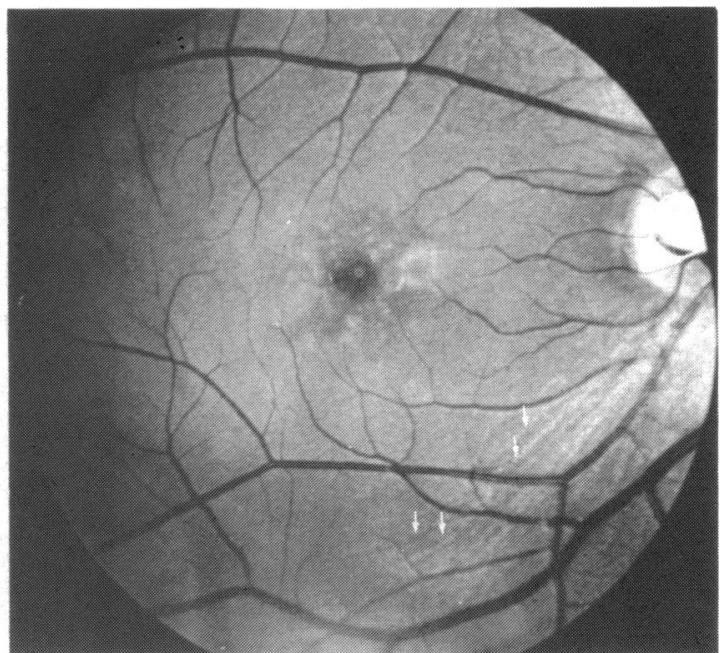

Fig. 1E Stargardt's dystrophy.

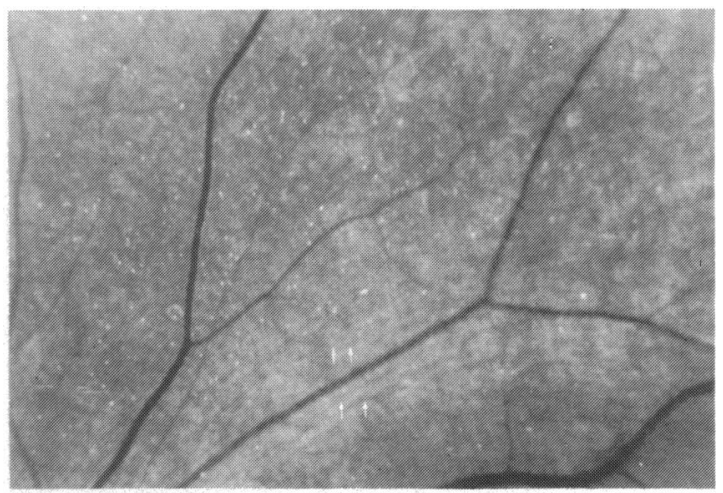

Fig. $1 \mathrm{~F}$ Rod-cone dystrophy.

$1.9 \log$ units elevated at 40 minutes. Visual fields were normal.

\section{Discussion}

We present eight examples of atrophy of the retinal nerve fibre layer in patients with outer retinal layer diseases. These changes are very frequently present when sought but may be difficult to detect against a background of generalised atrophy of the nerve fibre layer and/or retinal pigment epithelium and other pigmentary aberrations. In general the changes in the nerve fibre layer correlate well with the severity of the disease process. However, it is often difficult to link individual nerve fibre layer defects with specific field defects where there are also field defects due to the basic outer retinal layer disease process. Once nerve fibre layer atrophy appears, its progression 


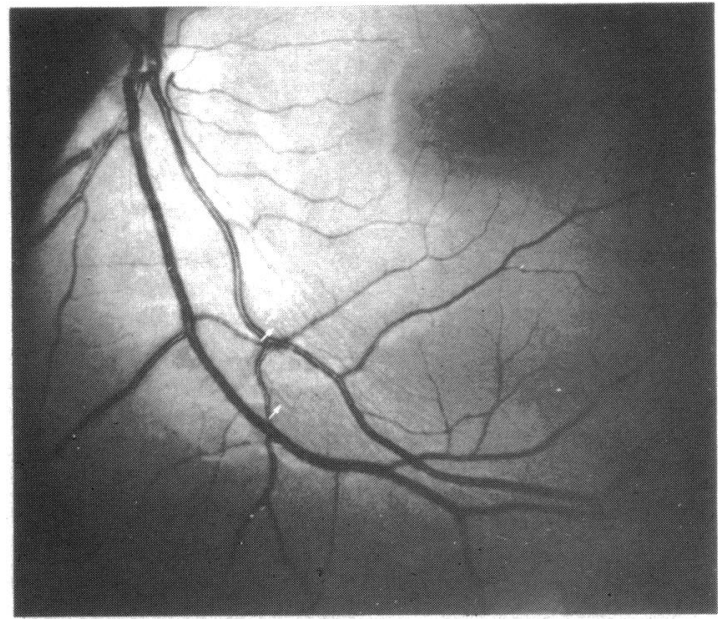

Fig. 1G Fundus flavimaculatus.

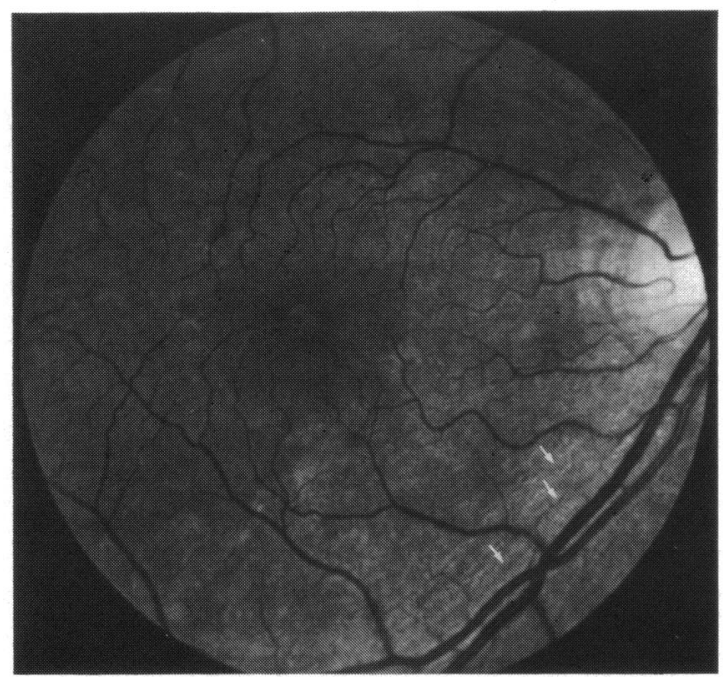

Fig. 1H Choroideraemia (carrier).

appears to parallel the progression of the disease, and when advanced stages of disease are reached, in which generalised retinal atrophy is present, the wedge-shaped defects have disappeared.

In previously reported cases of damage to the retinal nerve fibre layer the primary insult has been to the optic nerve or another portion of the ganglion cell axon, such as the chiasm. The consequent changes in the nerve fibre layer represent direct injury to that axon, not evidence of remote effects or transsynaptic degeneration.

Thus the discovery of changes in the nerve fibre layer in disorders of the outer retinal layer raises important questions about the pathogenesis of these changes. Is there transsynaptic degeneration, or do

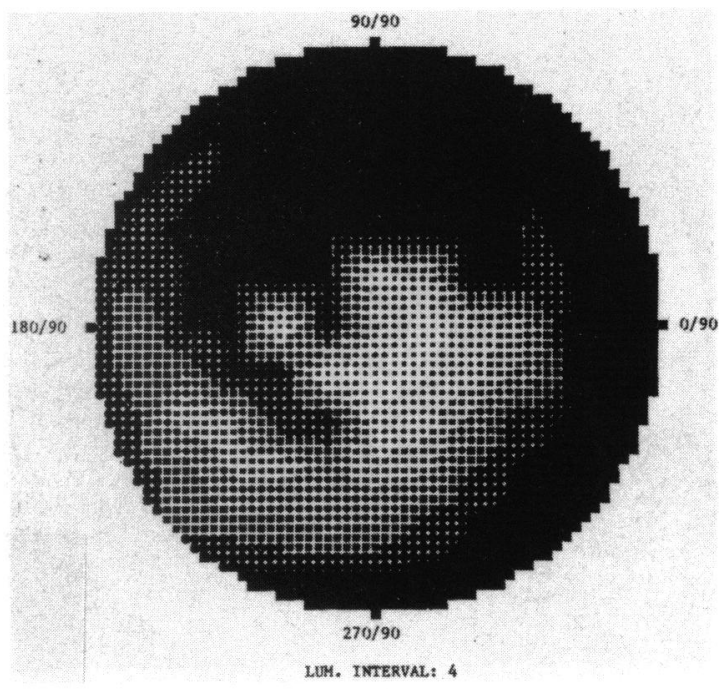

Fig. 2 Visual field of patient 2 (Octopus).

these diseases of outer retinal layers actually directly involve the inner retinal layers as well?

Transsynaptic degeneration has been thought to occur only rarely and to minor degrees in adult humans or animals. ${ }^{9}$ For this reason Hoyt and associates were able to point out the significance of one pattern of nerve fibre layer change (homonymous hemianopic hypoplasia) as indicative of congenital or very early injury to the postgeniculate central nervous system. ${ }^{10}$

If the diseases in question truly affect the outer retinal layers predominantly, then an explanation is needed for transsynaptic degeneration occurring after infancy.

Studies in monkeys confirm the clinical impression that transsynaptic degeneration is rare (or hard to detect) in the central nervous system of mature animals. Ablation of the striate cortex of immature monkeys produces approximately $70 \%$ loss of retinal ganglion cells, ${ }^{11}$ much less ganglion cell loss in adult animals. ${ }^{12}$

However, some retrograde transsynaptic degeneration does occur in adult monkeys. Dineen $e t$ al. ablated the striate cortex of adult monkeys and found a $30 \%$ loss of parafoveal retinal ganglion cells. ${ }^{12}$ In addition physiological evidence of transsynaptic transport of neural materials ${ }^{13}$ might provide a logical mechanism by which transsynaptic effects are mediated in adult animals.

INVOLVEMENT OF OUTER RETINAL LAYERS Electrophysiological studies suggest that some diseases generally considered to affect predominantly inner or outer retinal layers, but not both, 


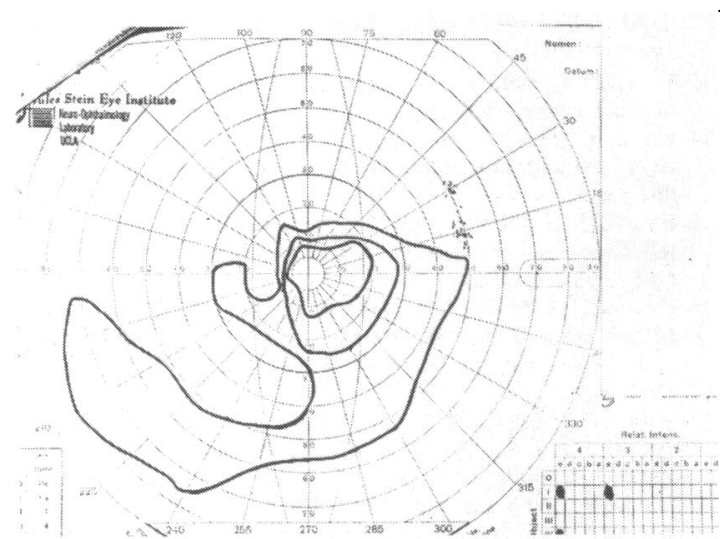

Fig. 3 Visual field of patient 2.

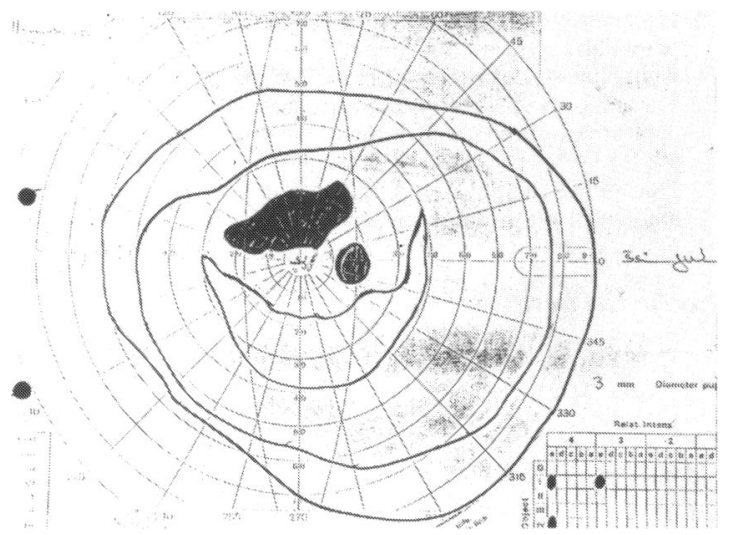

Fig. 4 Visual field of patient 3.

influence many retinal layers. Kirkham and Coupland found electroretinographic changes in papilloedema due to increased intracranial pressure, ${ }^{14}$ and Fazio et al. reported alterations of the single flash electroretinogram in advanced glaucoma. ${ }^{15}$ Both of these disease processes are thought to affect the ganglion cell axon primarily. The pattern electroretinogram is considered to reflect ganglion cell (or at least inner retinal) activity, ${ }^{16}$ but it is significantly diminished in Stargardt's disease, an outer retinal layer process ${ }^{17}$ (and Newman NM, Jackson JL, Latner B, personal communication).

Other aberrations of the ganglion cell axon are not uncommon in diseases of the outer retina. Clinically, waxy pallor of the optic disc has long been recognised as a sign in advanced rod-cone dystrophies, but neural atrophy has gone unnoted and is not discussed as a pathological feature of outer retinal layer disease. ${ }^{18}{ }^{19}$ Unusual drusen also are noted in retinitis

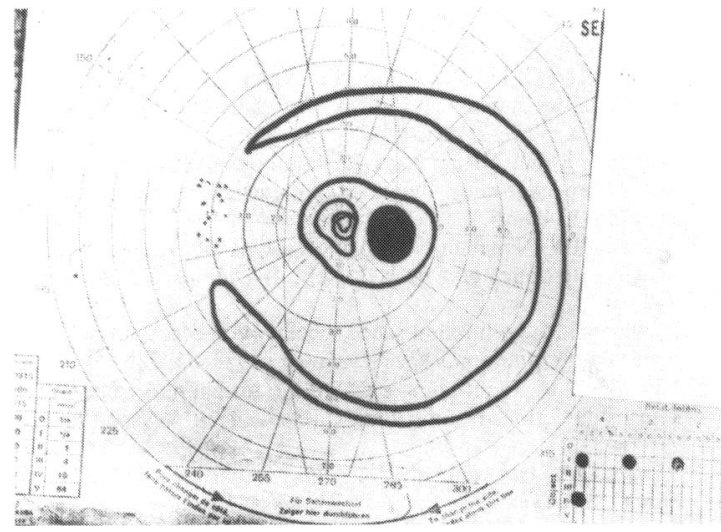

Fig. 5 Visual field of patient 6.

pigmentosa, frequently occurring in the nerve fibre layer away from the disc substance, in contrast to optic nerve head drusen which are confined to the papilla. ${ }^{20}$ In addition the temporal portion of the disc and its nerve fibre layer appear to be severely diminished or missing in patients with $X$-linked congenital stationary night blindness,${ }^{21}$ and similar changes and telangiectasis are extremely common in the cone-rod degenerations. ${ }^{2}$

Thus substantial anatomical, physiological, electrophysiological, and clinical evidence indicates nerve fibre layer involvement in outer retinal layer disease and is consistent with our observations of atrophic nerve fibre layer changes.

The observed changes appear to be signs of disease processes initiated in early, even prenatal, development because many of the changes we illustrate are found in children. Early outer retinal damage may cause transsynaptic changes. In primate studies on the retinal degeneration from striate cortex lesions the severity of transsynaptic degeneration was directly related both to age and to time ${ }^{23}$ - for example, the younger the animal and the longer the observation period following the injury, the greater the degeneration. Alternatively, some of the mentioned disease processes may involve metabolic and physiological changes which occur in many retinal layers but appear clinically as changes in the outer retinal layers predominantly.

Awareness of the occurrence of these changes in the nerve fibre layer in outer retinal layer disease has at least one practical implication. The presence of nerve fibre layer changes not readily explained by optic nerve disease should prompt examination of the patient for diseases of the outer retinal layer.

This project was supported in part by Research to Prevent Blindness, Inc., and a centre grant from the National Retinitis Pigmentosa Foundation. 


\section{References}

1 Quigley HA, Miller NR, George T. Clinical evaluation of nerve fibre layer atrophy as an indicator of glaucomatous optic nerve damage. Arch Ophthalmol 1980; 98: 1564-71.

2 Somer S, Miller NR, Pollack I, Maumenee AE, George T. The nerve fibre layer in the diagnosis of glaucoma. Arch Ophthalmol 1977; 95: 2149-56.

3 Stevens RA, Newman NM. Abnormal visual evoked potentials in eyes with optic nerve head drusen. Am J Ophthalmol 1981; 92: 857-62.

4 Newman NM. Ophthalmoscopic observation of the retinal nerve fiber layer. Ophthalmology (Rochester) 1977; 83: 786-96.

5 Newman NM. Ophthalmoscopy of the retinal nerve fiber layer. Use in detection of neurologic disease. Arch Neurol 1982; 39: 226-33.

6 Martin DA, Heckenlively JR. The normal electroretinogram. Doc Ophthalmol Proc Ser 1982; 31: 135-44.

7 Heckenlively JR. Hereditary retinal and choroidal degenerations. In: Emery A, Rimoin D, eds. Principles and practice of medical genetics. Edinburgh: Churchill, 1983: 522-38.

8 Foxman SG, Heckenlively JR, Bateman JB, Wirtschafter JD. The classification of congenital and early onset retinitis pigmentosa. Arch Ophthalmol 1985; 103: 1502-6.

9 Miller NR, Newman S. Transsynaptic degeneration. Arch Ophthalmol 1981; 99: 1654.

10 Hoyt WF, Rios-Montenegro EN, Behrens MM, Eckelhoff RJ. Homonymous hemioptic hypoplasia. Funduscopic features in standard and red-free illumination in three patients with congenital hemiplegia. Br J Ophthalmol 1972; 56: 537-45.

11 Van Buren JM. Transsynaptic retrograde denegeration in the visual system of primates. J Neurol Neurosurg Psychiatry 1963; 26: 402-9.

12 Dineen J, Hendrickson A, Keating EG. Alterations of retinal inputs following striate cortex removal in adult monkey. Exp Brain Res 1982; 47: 446-56.

13 Grafstein B, Laureno R. Transport of radioactivity from eye to the visual cortex in the mouse. Exp Neurol 1973; 39: 44-57.

14 Kirkham TH, Coupland SG. Abnormal electroretinograms and visual evoked potentials in chronic papilledema using time difference analysis. Can J Neurol 1981; 8: 243-8.

15 Fazio DT, Heckenlively JR, Martin DA, Infante R, Christensen RE. Changes in the ERG in advanced open angle glaucoma. Doc Ophthamol in press.

16 Fiorentini A, Maffei L, Pirchio M, Spinella D, Porciatti V. The ERG in response to alternating gratings in patients with diseases of the peripheral visual pathway. Invest Ophthalmol Vis Sci 1981; 21: $490-3$.

17 Arden GB, Carter RM, MacFarlan A. Pattern and Ganzfield electroretinograms in macular disease. $\mathrm{BrJ}$ Ophthalmol in press.

18 Retina. Yanoff M, Fine B, Ocular pathology. 2nd ed. Philadelphia: Harper and Row, 1982: 387-468.

19 Carr RE. Primary retinal degenerations. In: Duane TE, ed. Clinical Ophthalmology. Philadelphia: Harpur and Row, 1985: 3: 1-19.

20 Spencer WH. Drusen of the optic disk and aberrent axoplasmic transport. Am J Ophthalmol 1978; 85: 1-12.

21 Heckenlively JR. Loss of electroretinographic oscillatory potentials: optic atrophy, and dysplasia in congenital stationary night blindness. Am J Ophthalmol 1983; 96: 526-34.

22 Heckenlively JR, Martin DA, Rosales TR. Telangiectasia and optic atrophy in cone-rod degenerations. Arch Ophthalmol 1981; 99: 1983-91.

23 Dineen JT, Hendrickson AE. Age correlated differences in the amount of retinal degeneration of the striate cortex lesions in monkeys. Invest Ophthalmol Vis Sci 1981; 21: 749-52.

Accepted for publication 1 April 1986. 